TITLE:

\title{
Electrochemical surface plasmon resonance as a probe of redox reactions at the ionic liquid|gold interface
}

\section{AUTHOR(S):}

Nishi, Naoya; Ikeda, Yoichi; Sakka, Tetsuo

\section{CITATION:}

Nishi, Naoya ... [et al]. Electrochemical surface plasmon resonance as a probe of redox reactions at the ionic liquid|gold interface. Journal of Electroanalytical Chemistry 2018, 817: $210-216$

\section{ISSUE DATE:}

2018-05-15

URL:

http://hdl.handle.net/2433/254671

\section{RIGHT:}

(c) 2018. This manuscript version is made available under the CC-BY-NC-ND 4.0 license http://creativecommons.org/licenses/by-nc-nd/4.0/.; この論文は出版社版でありません 。引用の際には出版社版をご確認ご利用ください。; This is not the published version. Please cite only the published version. 


\title{
Electrochemical surface plasmon resonance as a probe of redox reactions at the ionic liquid|gold interface
}

\author{
Naoya Nishi*, Yoichi Ikeda, and Tetsuo Sakka
}

Department of Energy and Hydrocarbon Chemistry, Graduate School of Engineering, Kyoto University, Kyoto 615-8510, Japan

${ }^{*}$ Correspondence should be addressed

Tel: $+81-75-383-2491$

Email: nishi.naoya.7e@kyoto-u.ac.jp

\begin{abstract}
Electrochemical surface plasmon resonance (ESPR) has been employed as a probe of redox reactions at the interface between gold $(\mathrm{Au})$ and ionic liquid (IL). Two redox couples, ferrocene $(\mathrm{Fc}) / \mathrm{Fc}^{+}$and (ferrocenylmethyl)trimethylammonium $\left(\mathrm{FTA}^{+}\right) / \mathrm{FTA}^{2+}$, and two ILs, trioctylmethylammonium bis(trifluoromethanesulfonyl)amide ([TOMA $\left.\left.{ }^{+}\right]\left[\mathrm{C}_{1} \mathrm{C}_{1} \mathrm{~N}^{-}\right]\right)$and 1-butyl-3-methylimidazolium bis(trifluoromethanesulfonyl)amide $\left(\left[\mathrm{C}_{4} \mathrm{mim}^{+}\right]\left[\mathrm{C}_{1} \mathrm{C}_{1} \mathrm{~N}^{-}\right]\right)$have been studied. In the ESPR measurements, the shift of the SPR angle has been recorded simultaneously with cyclic voltammogram (CV). It has been revealed that the SPR angle shift reproduces $\mathrm{CV}$ when the former is semi-differentiated or the latter is semi-integrated, and, therefore, that the ESPR response probes the surface concentration of redox couples at the IL|Au interface. Among the four combination of the two redox couples and the two ILs, the case for $\mathrm{Fc} / \mathrm{Fc}^{+}$in $\left[\mathrm{TOMA}^{+}\right]\left[\mathrm{C}_{1} \mathrm{C}_{1} \mathrm{~N}^{-}\right]$shows significantly greater ESPR response than the other three cases. A model has been established for the relationship between the SPR angle shift and the surface concentration of redox species. The model predicts that the SPR angle shift becomes pronounced with increasing $D_{\mathrm{R}} / D_{\mathrm{O}}$, the diffusion coefficient ratio of the reduced (R) and oxidized (O) species when the reduced species is initially dissolved in the IL as is the case for the present study. Significantly greater $D_{\mathrm{R}} / D_{\mathrm{O}}$ for $\mathrm{Fc} / \mathrm{Fc}^{+}$in $\left[\mathrm{TOMA}^{+}\right]\left[\mathrm{C}_{1} \mathrm{C}_{1} \mathrm{~N}^{-}\right]$than the three other cases has been confirmed from the $D_{\mathrm{R}}$ and $D_{\mathrm{O}}$ measurements by $\mathrm{CV}$ with a microdisk electrode. The trend of the measured $D_{\mathrm{R}}$ and $D_{\mathrm{O}}$ values agrees with recent findings by researchers that small neutral solutes in ILs composed of large ions diffuse fast beyond the prediction of the Stokes-Einstein relation.
\end{abstract}

Keywords: electric double layer; interfacial structure; ultraslow dynamics; ultraslow relaxation; hysteresis; TFSA 


\section{Introduction}

Ionic liquids (ILs), which are liquid entirely composed of ions, have potential electrochemical applications s.2 $^{1,2}$ such as electrodeposition, ${ }^{3}$ lithium ion battery, ${ }^{4-6}$ dye-sensitized solar cell, ${ }^{7-9}$ redox flow battery, ${ }^{10,11}$ and electrochemical sensors. ${ }^{12}$ In view of the potential applications, electrode reactions (redox reactions) at the IL/electrode interface have extensively been studied. ${ }^{13-15}$ Among various electrode reactions, most fundamental ones are outer-sphere electron transfers such as those for metallocenes. Thermodynamic, ${ }^{16-20}$ kinetics, ${ }^{21-25}$ and diffusion ${ }^{24-28}$ properties related to the electrode reactions at the IL/electrode interface have been reported for ferrocene, its derivatives, and cobaltocene.

One of intriguing findings from a series of studies is the inequality of diffusion coefficients of reduced and oxidized forms, $D_{\mathrm{R}}$ and $D_{\mathrm{O}}$, of the metallocenes. ${ }^{18,23,24,29-35}$ In an extreme case, it was reported that $D_{\mathrm{R}} / D_{\mathrm{O}}$ is 7.80 for ferrocene/ferrocenium $\left(\mathrm{Fc} / \mathrm{Fc}^{+}\right)$redox couple in trihexyltetradecylphosphonium trifluorotris(pentafluoroethyl)phosphate, ${ }^{33}$ which is significantly greater than unity. If we regard the size of Fc and $\mathrm{Fc}^{+}$as the almost same from crystallographic ${ }^{36,37}$ and theoretical ${ }^{35}$ results, this inequality cannot be explained by the Stokes-Einstein relation that is based on hydrodynamics. Kaintz et al. compiled $D$ data for various kinds of solutes in ILs, which are not limited to redox couples, and compared them with hydrodynamically predicted ones from their sizes and bulk viscosity of the ILs. ${ }^{38,39}$ They found that the diffusion becomes prominently fast when solutes in ILs are neutral and are small compared with the IL ions. ${ }^{38,39}$ On the other hand, similarly small but charged solutes diffuse slower than the prediction, although the degree of the deviation is less than the neutral cases. ${ }^{38,39}$ The fast diffusion of small neutral solutes in ILs has later been confirmed by a comprehensive study. ${ }^{40}$ For such charged-state and size dependences of the diffusion of solutes in ILs, microscopic origin has recently been proposed by Margulis and coworkers. ${ }^{41,42}$ They focused on nano-sized phase separation between polar and apolar regions in ILs, (so called nano-segregation), which is known to be peculiar to ILs. ${ }^{43,44}$ Small charged and neutral solutes tend to stay in the polar and apolar regions, where they found the structure is stiff and soft, respectively, resulting in the slower and faster diffusion. ${ }^{41,42}$ The results of these studies can explain why the serious deviation of $D_{\mathrm{R}} / D_{\mathrm{O}}$ from unity happens for some redox species in ILs.

For the studies on the redox reactions at the ILlelectrode interface, current has mostly been used as a probe. In the present study, we focus on the electrochemical surface plasmon resonance (ESPR) $)^{45-48}$ as a probe. SPR can sensitively probe the refractive index change of dielectric media in the vicinity of the noble metal surface along which surface plasmon polariton propagates. ${ }^{49}$ Owing to this characteristics, ESPR has been used in electrochemical studies at the interface between metal electrode and dielectric electrolyte solutions for redox reactions of dissolved ${ }^{50-52}$ and surface-bound ${ }^{53-56}$ small molecules, and even bigger enzymes ${ }^{57-59}$ and polymers. ${ }^{60-63}$ Previously we applied ESPR to study the structural relaxation of electric double layer (EDL) at the ILlgold interface. ${ }^{64}$ ESPR enabled us to trace the change in the EDL structure of ILs responding to the electrode potential perturbation and to reveal ultraslow relaxation of the EDL structure of ILs on the order of $100 \mathrm{~s}$, which is likely to be caused by ionic multilayering, the spontaneous structure ordering of ILs at the 
interface $^{65-67}$ Here we extend the ESPR study on non-faradaic process to faradaic process at the IL/electrode interface. We will report in the present study that ESPR serves as a probe of the surface concentrations of redox couples at the IL/electrode interface and how the ESPR response is affected by the inequality of the diffusion coefficients of redox species in ILs, depending on the combination of the charged-state of the redox species and their relative size to IL ions.

\section{Experimental}

\subsection{Materials}

Trioctylmethylammonium bis(trifluoromethanesulfonyl)amide ([TOMA $\left.\left.{ }^{+}\right]\left[\mathrm{C}_{1} \mathrm{C}_{1} \mathrm{~N}^{-}\right]\right)$was prepared ${ }^{68}$ from $\left[\mathrm{TOMA}^{+}\right] \mathrm{Cl}^{-}$ (Alfa Aesar) and $\mathrm{H}^{+}\left[\mathrm{C}_{1} \mathrm{C}_{1} \mathrm{~N}^{-}\right]$(Central Glass) and then purified ${ }^{69}$ according to the method previously reported. 1-butyl-3-methylimidazolium bis(trifluoromethanesulfonyl)amide $\left(\left[\mathrm{C}_{4} \mathrm{mim}^{+}\right]\left[\mathrm{C}_{1} \mathrm{C}_{1} \mathrm{~N}^{-}\right]\right)$was similarly prepared by using $\mathrm{H}^{+}\left[\mathrm{C}_{1} \mathrm{C}_{1} \mathrm{~N}^{-}\right]$and synthesized ${ }^{70}\left[\mathrm{C}_{4} \mathrm{mim}^{+}\right] \mathrm{Cl}^{-}$. As redox species, $\mathrm{Fc}$ (Wako) and (ferrocenylmethyl)trimethylammonium $\left(\mathrm{FTA}^{+}\right)$were used. $\left[\mathrm{FTA}^{+}\right]\left[\mathrm{C}_{1} \mathrm{C}_{1} \mathrm{~N}^{-}\right]$was prepared by mixing an equimolar amount of $\left[\mathrm{FTA}^{+}\right] \mathrm{Br}^{-}$(TCI) and $\mathrm{H}^{+}\left[\mathrm{C}_{1} \mathrm{C}_{1} \mathrm{~N}^{-}\right]$in dichloromethane-water two-phase system followed by repeatedly washing of the dichloromethane solution of $\left[\mathrm{FTA}^{+}\right]\left[\mathrm{C}_{1} \mathrm{C}_{1} \mathrm{~N}^{-}\right]$with water to remove byproduct $\mathrm{HBr}$ and then evaporating dichloromethane from the solution. $\mathrm{Fc}$ or $\left[\mathrm{FTA}^{+}\right]\left[\mathrm{C}_{1} \mathrm{C}_{1} \mathrm{~N}^{-}\right]$was dissolved in the ILs. Before the ESPR and electrochemical measurements, the IL solution was pumped for $3 \mathrm{~h}$ by using an oil pump. This procedure is important to remove a trace amount of redox-active water and oxygen but is known to change the concentration of the redox species especially of Fc, due to sublimation. ${ }^{27}$ Therefore, the concentration of the redox species was determined by cyclic voltammogram (CV) using microdisk electrode (see Section 2.3 for the details).

\subsection{ESPR measurements}

Details of ESPR measurements were previously reported. ${ }^{64}$ Briefly, Springle (Kinetic Evaluation Instruments), was used for the ESPR apparatus with a Kretschmann configuration ${ }^{71}$ and with monochromatic light of a wavelength, $\lambda$, of $670 \mathrm{~nm}$. Gold film (50 nm thickness) deposited on a glass SF15 (with a refractive index, $n$, of 1.6911 at $670 \mathrm{~nm}$ ) was used as the working electrode (WE). The $n$ value of gold, $0.17408+3.6123 i$, was taken from literature, ${ }^{72}$ and those of $\left[\mathrm{TOMA}^{+}\right]\left[\mathrm{C}_{1} \mathrm{C}_{1} \mathrm{~N}^{-}\right]$and $\left[\mathrm{C}_{4} \mathrm{mim}^{+}\right]\left[\mathrm{C}_{1} \mathrm{C}_{1} \mathrm{~N}^{-}\right]$were determined to be 1.4080 and 1.4344, respectively, from spectroscopic ellipsometry of the surface of the ILs. ${ }^{73} \mathrm{~A} \mathrm{AgCl}-$ coated Ag wire and a Pt wire was directly immersed in the IL as the quasi-reference electrode (QRE) and the counter electrode (CE), respectively. The potential of WE with respect to QRE, denoted as $E$, was controlled using a PC-controlled potentiostat (Autolab type III). During the measurements, temperature was monitored and controlled at $25.00 \pm 0.05^{\circ} \mathrm{C}$ by flowing temperature-controlled water in the jacket of the cell and Ar gas (99.9\%) was kept flowing over the surface of the IL. The time variation, $\Delta \theta$, of the SPR resonant angle that is the 
incident angle of the light at which the reflectivity becomes minimum due to SPR was recorded simultaneously with CV.

\subsection{CV using microdisk electrode}

$\mathrm{CV}$ was performed using a Pt microdisk electrode with a surface diameter of $10 \mu \mathrm{m}$ as WE to evaluate $D_{\mathrm{R}}, D_{\mathrm{O}}$, and $C_{\mathrm{R} \text {,bulk }}$, the dissolved concentration of the reduced form $\left(\mathrm{Fc}\right.$ or $\left.\mathrm{FTA}^{+}\right)$. Two-electrode system was employed with a AgCl-coated Ag wire as QRE and CE, and E was controlled using a PC-controlled potentiostat (HECS972, Fuso) with a head box (972-1SK, Fuso). Temperature was controlled at $25^{\circ} \mathrm{C}$. Measured CVs at various scan rates were fitted with digital simulation using the finite element method (COMSOL Multiphysics 4.1). The electrode reaction was assumed to be reversible. The fitting parameters were the formal potential, $E^{0}$, and the uncompensated resistance, $R_{\mathrm{u}}$, along with $D_{\mathrm{R}}, D_{\mathrm{O}}$, and $C_{\mathrm{R}, \text { bulk }}$.

\section{Model}

In this section we derive a model equation for the change in $\Delta \theta$ due to the electrode reaction of redox-active species dissolved in an IL that covers the surface of the electrode made of gold film. Three phases for Kretschmann-type SPR system were assumed: prism (Phase 1), gold film (Phase 2), and the diffusion layer (Phase 3) in the IL where the reduced form of the species, R, is initially dissolved with a concentration of $C_{\mathrm{R}, \text { bulk }}$. The diffusion layer can be regarded as a uniform layer on top of the gold film because it is significantly thicker than the depth of the evanescent field penetrated into IL from the IL/gold interface. This assumption has already been proposed in a model analysis of redox reaction in an electrolyte solution by Shan et al. ${ }^{52}$ Because $^{2}$ ILs have significantly higher viscosity than electrolyte solutions and therefore form thinner diffusion layer, we confirmed whether the assumption is valid even for ILs. For a typical example, the diffusion layer thickness, $d$, is calculated from $d$ for semi-infinite linear diffusion, $d=(\pi D t)^{1 / 2}$, combined with characteristic time for $\mathrm{CV}, t=R T /(F v)$, by choosing the lowest diffusion coefficient, $D=0.8 \times 10^{-12} \mathrm{~m}^{2} \mathrm{~s}^{-1}$, and the highest scan rate, $v=0.05 \mathrm{~V} \mathrm{~s}^{-1}$, in the present study to evaluate the smallest $d$. Here, $R$ is the gas constant, $T=298.15 \mathrm{~K}$ is the absolute temperature, and $F$ is the Faraday constant. Even this smallest $d$ value, which was calculated to be $1.1 \mu \mathrm{m}$, is 6 times greater than the penetration depth of the evanescent field, $0.18 \mu \mathrm{m}$, which was calculated using $\left(\operatorname{Im}\left[\left(2 \pi n_{3} / \lambda\right) \sqrt{1-\left(n_{1} \sin \theta_{1} / n_{3}\right)^{2}}\right]\right)^{-1} .{ }^{49}$ Here $\theta_{1}$ is the SPR resonant angle of the incident light in Phase 1 where the reflectivity shows a minimum value in the reflectivity dip.

The SPR resonant angle, $\theta_{1}$, can be related with the refractive indices, $n_{i}$, for the three phases. ${ }^{49}$

$$
n_{1} \sin \theta_{1}=\sqrt{\frac{n_{3}^{2} \operatorname{Re}\left(n_{2}^{2}\right)}{\operatorname{Re}\left(n_{2}^{2}\right)+n_{3}^{2}}}
$$

where it is assumed that $n_{1}$ (prism) and $n_{3}$ (IL) are real and that $n_{2}$ (gold) is complex. 
The Lorentz-Lorenz equation ${ }^{74,75}$ represents $n_{3}$ by the surface concentration, $C_{\mathrm{i}}$, for the species i at the IL $\mid$ gold interface.

$$
n_{3}=\sqrt{1+\frac{x}{1-x / 3}}
$$

where

$$
\begin{aligned}
x & =4 \pi N_{\mathrm{A}} \sum_{\mathrm{i}} \alpha_{\mathrm{i}} C_{\mathrm{i}} \\
& =4 \pi N_{\mathrm{A}}\left(\alpha_{\mathrm{R}} C_{\mathrm{R}}+\alpha_{\mathrm{O}} C_{\mathrm{O}}+\alpha_{\mathrm{C}} C_{\mathrm{C}}+\alpha_{\mathrm{A}} C_{\mathrm{A}}\right)
\end{aligned}
$$

and $N_{\mathrm{A}}$ is the Avogadro constant, and $\alpha_{\mathrm{i}}$ is the polarizability volume at $670 \mathrm{~nm}$ for the species $\mathrm{i}=\mathrm{C}, \mathrm{A}, \mathrm{R}$, and $\mathrm{O}$ denoting the IL cation and anion, and the reduced and oxidized forms of the redox-active species, respectively. The flux balance between $\mathrm{R}$ and $\mathrm{O}$ at the IL/gold interface during the electrode reaction, which is termed the Faraday-Fick relation, ${ }^{76}$ is

$$
\sqrt{D_{\mathrm{R}}}\left(C_{\mathrm{R}, \text { bulk }}-C_{\mathrm{R}}\right)=\sqrt{D_{\mathrm{O}}} C_{\mathrm{O}}
$$

From Eqs. (1-3), a linear relationship may be obtained between the SPR angle shift, $\Delta \theta \equiv \theta_{1}\left(C_{\mathrm{R}}\right)-\theta_{1}\left(C_{\mathrm{R}, \text { bulk }}\right)$, and the concentration decrease, $\Delta C_{\mathrm{R}} \equiv C_{\mathrm{R}, \text { bulk }}-C_{\mathrm{R}}$, by the Taylor expansion.

$$
\Delta \theta=\frac{1}{2} n_{1}^{2} \frac{\sin ^{3} \theta_{1}}{\cos \theta_{1}} \frac{b}{(1+2 a / 3)^{2}} \Delta C_{\mathrm{R}}
$$

where

$$
\begin{aligned}
& a=4 \pi N_{\mathrm{A}}\left\{\alpha_{\mathrm{C}} C_{\mathrm{C}}+\alpha_{\mathrm{A}} C_{\mathrm{A}}+\alpha_{\mathrm{R}} C_{\mathrm{R}, \text { bulk }}\right\} \\
& b=4 \pi N_{\mathrm{A}}\left(\sqrt{\frac{D_{\mathrm{R}}}{D_{\mathrm{O}}}} \alpha_{\mathrm{O}}-\alpha_{\mathrm{R}}\right)
\end{aligned}
$$

Comparison of numerical calculations with and without the linear approximation for the condition of Fig.1 showed that the linear approximation leads to $0.7 \%$ underestimation of $\Delta \theta$ at a maximum where $\Delta C_{\mathrm{R}}=C_{\mathrm{R} \text {,bulk }}$ and $C_{\mathrm{R}}=0$, which is substantially negligible. Eq.(4) demonstrates that the proportionality constant includes not only the refractive indices $\left(n_{1}, n_{2}, n_{3}\right)$ of the system but also optical $(\alpha)$ and hydrodynamic $(D)$ properties of the redox species in the parameters $a$ and $b$. To separate the refractive index part from the contribution of redox species in the proportionality constant, further approximation may be helpful. Because the $\alpha$ values are comparable in the parameter $a$ but the concentration of IL, $C_{\mathrm{C}}=C_{\mathrm{A}}$, on the order of $1 \mathrm{M}$, is two orders of magnitude higher than that of redox species for the ESPR measurements, we omit the $\alpha_{\mathrm{R}} C_{\mathrm{R}, \text { bulk }}$ term from the parameter $a$ and separate the proportionality constant into two parts, $A$ and the other,

$$
\Delta \theta=A\left(\sqrt{\frac{D_{\mathrm{R}}}{D_{\mathrm{O}}}} p-1\right) \alpha_{\mathrm{R}} \Delta C_{\mathrm{R}}
$$

where

$$
A=2 \pi N_{\mathrm{A}} n_{1}^{2} \frac{\sin ^{3} \theta_{1}}{\cos \theta_{1}}\left(1+\frac{2}{3} a^{\prime}\right)^{-2}
$$


with

$$
a^{\prime}=4 \pi N_{\mathrm{A}}\left\{\alpha_{\mathrm{C}} C_{\mathrm{C}}+\alpha_{\mathrm{A}} C_{\mathrm{A}}\right\}
$$

and $p=\alpha_{\mathrm{O}} / \alpha_{\mathrm{R}}$. The parameter $A$ is irrelevant to redox species and $a^{\prime}$ shown in $A$ can be evaluated from the Lorentz-Lorenz relation (similarly to Eq.(2)) in combination with a measured value of $n$ of the neat IL and therefore we do not need to evaluate $\alpha_{\mathrm{C}}$ and $\alpha_{\mathrm{A}}$. Eq.(5) can be used to analyze the ESPR response during the electrochemical measurements. $\Delta \theta$ reaches at the limiting value, $\Delta \theta_{\mathrm{lim}}$ at the limiting-current potentials where $\Delta C_{\mathrm{R}}=C_{\mathrm{R}, \text { bulk }}$ and $C_{\mathrm{R}}=0$ and therefore we obtain

$$
\frac{\Delta \theta_{\mathrm{lim}}}{C_{\mathrm{R}, \mathrm{bulk}}}=A\left(\sqrt{\frac{D_{\mathrm{R}}}{D_{\mathrm{O}}}} p-1\right) \alpha_{\mathrm{R}}
$$

Eq.(6) can be used to compare several combinations of redox species and ILs. $\Delta \theta_{\text {lim }} / C_{\mathrm{R}, \text { bulk }}$ in the left-hand side is termed ESPR sensitivity in the present study, which depends on the combination.

\section{Results and Discussion}

The ESPR measurements were performed simultaneously with CV. Figure 1a shows CVs at the gold interface of $\left[\mathrm{TOMA}^{+}\right]\left[\mathrm{C}_{1} \mathrm{C}_{1} \mathrm{~N}^{-}\right]$with the presence (solid lines) and the absence (dashed lines) of $25 \mathrm{mM} \mathrm{Fc}$ at three scan rates: 10,30 , and $50 \mathrm{mV} \mathrm{s}^{-1}$. In the absence of $\mathrm{Fc}$ (dashed lines), we observed negligibly small residual and non-Faradaic current. In the presence of $\mathrm{Fc}$ (solid lines), one can see positive current due to the oxidation of $\mathrm{Fc}$ in the forward scan and negative current due to the reduction of the generated $\mathrm{Fc}^{+}$in the backward scan. The positive current is discernible as a peak only for $10 \mathrm{mV} \mathrm{s}^{-1}$, the slowest scan rate, at $0.6 \mathrm{~V}$ although the negative peaks can be seen for all the scan rates. The separation between the positive and negative peaks at 10 $\mathrm{mV} \mathrm{s}^{-1}$ is around $0.7 \mathrm{~V}$, which is significantly wider than $0.06 \mathrm{~V}$ predicted for reversible redox reaction. This is due to $I R$ drop originated from uncompensated resistance in $\left[\mathrm{TOMA}^{+}\right]\left[\mathrm{C}_{1} \mathrm{C}_{1} \mathrm{~N}^{-}\right]$. As will be shown below, only at $10 \mathrm{mV} \mathrm{s}^{-1}$ the surface concentration of $\mathrm{Fc}$ at the IL/gold interface substantially becomes zero.

Figure $1 \mathrm{~b}$ shows $\Delta \theta$ obtained by the ESPR measurements during recording the CVs in Fig.1a. In contrast to the CVs, $\Delta \theta$ clearly shows the potential-dependence even in the absence of $\mathrm{Fc}$ (dashed lines). This demonstrates that $\Delta \theta$ sensitively probes the change in the EDL structure responding to the potential scan. During the forward scan going to more positive potentials, the $\Delta \theta$ values decrease and for the backward scan they increase back. However, $\Delta \theta$ for the backward scan deviates to larger values from that for the forward scan. This potential hysteresis of $\Delta \theta$ is caused by the ultraslow relaxation of the EDL structure of ILs, previously reported by us ${ }^{64,77,78}$ and other researchers. ${ }^{79-81}$ In our previous ESPR study ${ }^{64}$ on the ultraslow relaxation, the response of $\Delta \theta$ against potential steps was examined. After a positive (negative) potential step, $\Delta \theta$ negatively (positively) jumped, followed by the positive (negative) ultraslow decay on the order of $100 \mathrm{~s}$ (see Fig.S1). ${ }^{64}$ The former fast response of $\Delta \theta$ is ascribable to fast polarization relaxation such as electronic and orientational polarization of IL ions at the first ionic layer in contact with the gold surface. The latter slow response is 
due to ionic polarization ${ }^{82}$ at the interface, which is collective translation of ions corresponding to charging process of EDL. Such response of $\Delta \theta$ against the potential steps can explain the hysteretic behavior of $\Delta \theta$ during the potential scan shown in Fig.1b. According to the theory of the transfer function, sweep response function can be obtained by the convolution of step input function and step response function. By using this relationship, the sweep response of $\Delta \theta$ was semi-quantitatively simulated from the step response of $\Delta \theta$ previously obtained. ${ }^{64}$ The results (shown in Fig.S2) are in good agreement with the dashed lines in Fig.1b, illustrating that the hysteresis of $\Delta \theta$ during the potential scan is caused by the ultraslow relaxation of the EDL structure of ILs.

When Fc was dissolved in $\left[\mathrm{TOMA}^{+}\right]\left[\mathrm{C}_{1} \mathrm{C}_{1} \mathrm{~N}^{-}\right]$, the response of $\Delta \theta$ dramatically changed, as shown by the solid lines in Fig.1b. $\Delta \theta$ varies with the electrode reaction of $\mathrm{Fc} / \mathrm{Fc}^{+}$shown in $\mathrm{CVs}$ (solid lines in Fig.1a). At positive potentials in the forward scan $\Delta \theta$ positively shifted and in the backward scan it went back to the baseline without Fc (dashed lines). The positive shift in $\Delta \theta$ originates from the increase (decrease) in the surface concentration of $\mathrm{Fc}^{+}(\mathrm{Fc})$. Because $\Delta \theta$ generally shifts to positive with increasing the refractive index of the dielectric in contact with the gold film, $\mathrm{Fc}^{+}$generated at positive potentials seems to have higher polarizability than Fc according the Lorentz-Lorenz relation in Eq.(2). The EDL contribution was eliminated from $\Delta \theta$ by the subtraction of the baselines (dashed lines in Fig.1b) from the $\Delta \theta$ curves with Fc (solid lines in Fig.1b). This subtraction is based on the assumption that the existence of $\mathrm{Fc}$ and $\mathrm{Fc}^{+}$at this level of concentration $(25 \mathrm{mM})$ makes negligible effect on the EDL structure. The subtracted $\Delta \theta$ curves are shown in Fig.1c as solid lines. If $\Delta \theta$ reflects the surface concentrations of the redox couple $\left(\mathrm{Fc} / \mathrm{Fc}^{+}\right)$as predicted in Eqs.(4) and (5), it should reproduce the behavior of semi-integrated CVs, which is known as a measure of the surface concentrations. ${ }^{76,83}$ The CVs in Fig.1a were numerically semi-integrated (after the baseline subtraction) and the results were shown in Fig.1c as open circles. It was found that $\Delta \theta$ agrees with the semiintegrated $\mathrm{CVs}$, indicating that $\Delta \theta$ can be used as a probe of the redox couple and the redox reaction at the IL/gold interface. It should be noted that the limiting current in semi-integrated CVs is determined with $D_{\mathrm{R}}$ and $C_{\mathrm{R} \text {,bulk }}$ whereas that in the ESPR response is affected not only by the two but also by $D_{\mathrm{O}}, \alpha_{\mathrm{R}}$, and $\alpha_{\mathrm{O}}$, as shown in Eq.(6) and as will be discussed below. In the opposite direction, it is expected that semi-differentiation of $\Delta \theta$ should reproduce $\mathrm{CVs}$, as was shown by Shan et al. for electrode reaction in an electrolyte solution. ${ }^{52}$ Indeed, the semi-differentiated $\Delta \theta$ (open circles in Fig.1a) well agrees with the CVs.

In Fig.1c, $\Delta \theta$ and semi-integrated current at $10 \mathrm{mV} \mathrm{s}^{-1}$ reach plateau at positive potentials, limitingcurrent region where $C_{\mathrm{R}}=0$. At the faster scan rates, 30 and $50 \mathrm{mV} \mathrm{s}^{-1}$, the potential scan until $0.8 \mathrm{~V}$ is not enough to observe the plateau, due to $I R$ drop. The $\Delta \theta$ value at the limiting-current region, $\Delta \theta_{\text {lim }}$, can be expressed as Eq.(6) that contains optical $(\alpha)$ and hydrodynamic $(D)$ properties of redox species, which will be discussed below

For the other combination of the redox couples and the ILs, similar ESPR measurements were carried out. We used the two ILs, $\left[\mathrm{TOMA}^{+}\right]\left[\mathrm{C}_{1} \mathrm{C}_{1} \mathrm{~N}^{-}\right]$and $\left[\mathrm{C}_{4} \mathrm{mim}^{+}\right]\left[\mathrm{C}_{1} \mathrm{C}_{1} \mathrm{~N}^{-}\right]$that are composed of the same anion $\mathrm{C}_{1} \mathrm{C}_{1} \mathrm{~N}^{-}$but different cations $\mathrm{TOMA}^{+}$and $\mathrm{C}_{4} \mathrm{mim}^{+}$. We used the two redox couples, $\mathrm{Fc} / \mathrm{Fc}^{+}$and 
FTA $^{+} / \mathrm{FTA}^{2+}$, which have different charged state in their reduced and oxidized forms. We evaluated the size of these IL ions and redox species by using quantum chemical calculation. The results are listed in Table 1. $\mathrm{TOMA}^{+}$is three times larger than $\mathrm{C}_{4} \mathrm{mim}^{+}$and similarly larger than the other species (Table 1). We would like to see the effect of the prominently fast diffusion of solutes in ILs, when the solute is neutral and smaller than the IL ions, ${ }^{38,39}$ as discussed in Introduction. In the present study, this is the case for Fc in $\left[\mathrm{TOMA}^{+}\right]\left[\mathrm{C}_{1} \mathrm{C}_{1} \mathrm{~N}^{-}\right]$. We thus studied the four combinations of the two redox couples and the two ILs, including the case, $\mathrm{Fc} / \mathrm{Fc}^{+}$in $\left[\mathrm{TOMA}^{+}\right]\left[\mathrm{C}_{1} \mathrm{C}_{1} \mathrm{~N}^{-}\right]$as already introduced in Fig.1. The ESPR results of the four combinations are shown in Fig.2. Fig.2a is for $\mathrm{Fc} / \mathrm{Fc}^{+}$in $\left[\mathrm{TOMA}^{+}\right]\left[\mathrm{C}_{1} \mathrm{C}_{1} \mathrm{~N}^{-}\right]$as in Fig.1c, but in the vertical axis shown is $\Delta \theta$ normalized with $C_{\mathrm{R}, \text { bulk }}$ as in Eq.(6) to focus $\alpha$ and $D$. Fig.2b shows $\mathrm{FTA}^{+} / \mathrm{FTA}^{2+}$ in the same IL. One can see similar $\Delta \theta$ behavior to the $\mathrm{Fc} / \mathrm{Fc}^{+}$; at the low scan rate $\left(10 \mathrm{mV} \mathrm{s}{ }^{-1}\right)$ the plateau at positive potentials is discernible while at the higher scan rates $I R$ drop hinders the approach of $\Delta \theta$ to the plateau. However, the plateau values of $\Delta \theta C_{\mathrm{R}, \mathrm{bulk}}^{-1}$ in Fig.2b is significantly smaller than that in Fig.2a. Because this difference in the plateau value may stem from the difference in the redox species, we compared these two redox couples in another IL, $\left[\mathrm{C}_{4} \mathrm{mim}^{+}\right]\left[\mathrm{C}_{1} \mathrm{C}_{1} \mathrm{~N}^{-}\right]$. Figs.2c and $2 \mathrm{~d}$ are the ESPR results for Fc/Fc and $\mathrm{FTA}^{+} / \mathrm{FTA}^{2+}$ in $\left[\mathrm{C}_{4} \mathrm{mim}^{+}\right]\left[\mathrm{C}_{1} \mathrm{C}_{1} \mathrm{~N}^{-}\right]$, respectively. These ESPR responses exhibited sigmoidal behavior much less distorted than in $\left[\mathrm{TOMA}^{+}\right]\left[\mathrm{C}_{1} \mathrm{C}_{1} \mathrm{~N}^{-}\right]$because $\left[\mathrm{C}_{4} \mathrm{mim}^{+}\right]\left[\mathrm{C}_{1} \mathrm{C}_{1} \mathrm{~N}^{-}\right]$has conductivity much higher than $\left[\mathrm{TOMA}^{+}\right]\left[\mathrm{C}_{1} \mathrm{C}_{1} \mathrm{~N}^{-}\right]$and therefore has much smaller $I R$ drop. At all the three scan rates, the plateau was observed although the plateau values are slightly different, which is probably due to the combination of the non-negligible influence of the dissolved redox species on the EDL structure ${ }^{34}$ and the ultraslow dynamics of the EDL structure. ${ }^{64,77-81}$ In spite of the difficulty to uniquely determine the plateau values for these two cases, the values are similar to that in Fig.2b, the case for $\mathrm{FTA}^{+} / \mathrm{FTA}^{2+}$ in $\left[\mathrm{TOMA}^{+}\right]\left[\mathrm{C}_{1} \mathrm{C}_{1} \mathrm{~N}^{-}\right]$. Consequently, among the four cases in Fig.2, only Fc/Fc $\mathrm{Fc}^{+}$in $\left[\mathrm{TOMA}^{+}\right]\left[\mathrm{C}_{1} \mathrm{C}_{1} \mathrm{~N}^{-}\right]$(Fig.2a) exhibits exceptionally high plateau value.

The exceptionally high plateau value for $\mathrm{Fc} / \mathrm{Fc}^{+}$in $\left[\mathrm{TOMA}^{+}\right]\left[\mathrm{C}_{1} \mathrm{C}_{1} \mathrm{~N}^{-}\right]$can be considered using Eq.(6).

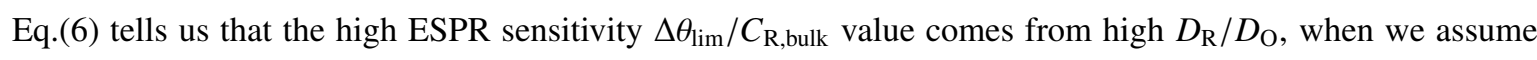
independence of $\alpha_{\mathrm{R}}$ and $\alpha_{\mathrm{O}}$ on the redox species and the ILs as solvents. To determine the $D_{\mathrm{R}}$ and $D_{\mathrm{O}}$ for the four cases, we performed $\mathrm{CV}$ using a microdisk electrode, at various scan rates where the geometry of the diffusion layer is mixed with linear and spherical ones. From the curve fitting using digital simulation, we independently determined $D_{\mathrm{R}}$ and $D_{\mathrm{O}}$. The measured and fitted CVs are shown in Figs.S3-S6 and the resultant $D_{\mathrm{R}}$ and $D_{\mathrm{O}}$ values are listed in Table 2. Overall, the $D_{\mathrm{R}}$ and $D_{\mathrm{O}}$ values in $\left[\mathrm{TOMA}^{+}\right]\left[\mathrm{C}_{1} \mathrm{C}_{1} \mathrm{~N}^{-}\right]$are one order of magnitude smaller than those in $\left[\mathrm{C}_{4} \mathrm{mim}^{+}\right]\left[\mathrm{C}_{1} \mathrm{C}_{1} \mathrm{~N}^{-}\right]$, corresponding to bulk viscosity difference (530 and $49 \mathrm{mPa} / \mathrm{s}$ at $25^{\circ} \mathrm{C}$ for $\left[\mathrm{TOMA}^{+}\right]\left[\mathrm{C}_{1} \mathrm{C}_{1} \mathrm{~N}^{-}\right]$and $\left[\mathrm{C}_{4} \mathrm{mim}^{+}\right]\left[\mathrm{C}_{1} \mathrm{C}_{1} \mathrm{~N}^{-}\right]$, respectively). However, $\mathrm{Fc}$ in $\left[\mathrm{TOMA}^{+}\right]\left[\mathrm{C}_{1} \mathrm{C}_{1} \mathrm{~N}^{-}\right]$has high $D$, which is comparable to that in $\left[\mathrm{C}_{4} \mathrm{mim}^{+}\right]\left[\mathrm{C}_{1} \mathrm{C}_{1} \mathrm{~N}^{-}\right]$. As a result, $D_{\mathrm{R}} / D_{\mathrm{O}}$ ratio for $\mathrm{Fc} / \mathrm{Fc}^{+}$in $\left[\mathrm{TOMA}^{+}\right]\left[\mathrm{C}_{1} \mathrm{C}_{1} \mathrm{~N}^{-}\right]$becomes high, 6.7, which is significantly greater than unity. This inequality of $D_{\mathrm{R}}$ and $D_{\mathrm{O}}$ for the almost same size $\mathrm{Fc}$ and $\mathrm{Fc}^{+35-37}$ cannot be explained from the viewpoint of hydrodynamics where diffusion coefficient is inversely proportional to the size of the solute. This level of high $D_{\mathrm{R}} / D_{\mathrm{O}}$ for $\mathrm{Fc} / \mathrm{Fc}^{+}$has been reported for an IL composed of large ions, trihexyltetradecylphospho- 
nium trifluorotris(pentafluoroethyl)phosphate, where $D_{\mathrm{R}} / D_{\mathrm{O}}=7.80 .{ }^{33}$ When we change the redox couples to $\mathrm{FTA}^{+} / \mathrm{FTA}^{2+}$, where both of the reduced and oxidized forms have charge on them, $D_{\mathrm{R}} / D_{\mathrm{O}}$ decreases from 6.8 to 2.0 (Table 2), although it still deviates from unity. When we change the IL to $\left[\mathrm{C}_{4} \mathrm{mim}^{+}\right]\left[\mathrm{C}_{1} \mathrm{C}_{1} \mathrm{~N}^{-}\right]$, whose cation is much smaller than $\mathrm{TOMA}^{+}$(Table 1 ), the $D_{\mathrm{R}} / D_{\mathrm{O}}$ ratios for the two redox couples decrease to 1.3 , close to unity. These results agree with the recent finding that diffusion becomes significantly faster than the hydrodynamics prediction when a solute in an IL is neutral and is smaller than the IL ions, ${ }^{38,39}$ as described in Introduction. Among the four combinations (eight cases of the four solutes, $\mathrm{Fc} / \mathrm{Fc}^{+}$and $\mathrm{FTA}^{+} / \mathrm{FTA}^{2+}$, in either of $\left[\mathrm{TOMA}^{+}\right]\left[\mathrm{C}_{1} \mathrm{C}_{1} \mathrm{~N}^{-}\right]$or $\left[\mathrm{C}_{4} \mathrm{mim}^{+}\right]\left[\mathrm{C}_{1} \mathrm{C}_{1} \mathrm{~N}^{-}\right]$), only $\mathrm{Fc}$ in $\left[\mathrm{TOMA}^{+}\right]\left[\mathrm{C}_{1} \mathrm{C}_{1} \mathrm{~N}^{-}\right]$fulfills the condition for extra hydrodynamic fast diffusion: neutral solute and large IL ions. That is why the $D_{\mathrm{R}} / D_{\mathrm{O}}$ for only $\mathrm{Fc} / \mathrm{Fc}^{+}$in $\left[\mathrm{TOMA}^{+}\right]\left[\mathrm{C}_{1} \mathrm{C}_{1} \mathrm{~N}^{-}\right]$is greater than the other cases.

To quantitatively analyze the ESPR plateau, Eq.(6) was used. We assumed that $\alpha_{\mathrm{O}}, \alpha_{\mathrm{R}}$, and $A$ are the same for the four combinations. The calculated $A$ values for $\left[\mathrm{TOMA}^{+}\right]\left[\mathrm{C}_{1} \mathrm{C}_{1} \mathrm{~N}^{-}\right]$and $\left[\mathrm{C}_{4} \mathrm{mim}^{+}\right]\left[\mathrm{C}_{1} \mathrm{C}_{1} \mathrm{~N}^{-}\right]$was 0.576 and $0.555 \mathrm{mdeg} \mathrm{mM}^{-1} \AA^{-3}$, respectively. Their difference is $4 \%$, non-negligible, but does not affect the discussion below where we used $A=0.56$. The ESPR plateau values (Fig.2) as a function of $D_{\mathrm{R}} / D_{\mathrm{O}}$, obtained microdisk electrode CVs (Table 2), was fitted using Eq.(6) with two fitting parameters, $p$ and $\alpha_{\mathrm{R}}$. The plot and the fitting result are shown in Fig.3. The fitted parameters were $p=1.2$ and $\alpha_{\mathrm{R}}=1.9 \AA^{3}$. The $p$ value higher than unity agrees with the behavior of the ESPR response; the increase in the $\Delta \theta$ values at positive potentials where the oxidized form dominates the diffusion layer (Figs.1 and 2). The $\alpha_{\mathrm{R}}$ value is one order of magnitude smaller than the reported value of Fc, $19 \AA^{3}{ }^{34}$ The small $\alpha_{\mathrm{R}}$ value comes from the ESPR sensitivity $\Delta \theta_{\text {lim }} / C_{\mathrm{R}, \text { bulk }}$ value for $\mathrm{Fc} / \mathrm{Fc}^{+}$in $\left[\mathrm{TOMA}^{+}\right]\left[\mathrm{C}_{1} \mathrm{C}_{1} \mathrm{~N}^{-}\right]$, where $D_{\mathrm{R}} / D_{\mathrm{O}}$ is high. When $D_{\mathrm{R}} / D_{\mathrm{O}}$ is greater than unity, as predicted in the Faraday-Fick relation, Eq.(3), oxidized species is accumulated at the electrode surface at a greater extent of the depletion of the reduced species (the extent is $\sqrt{D_{\mathrm{R}} / D_{\mathrm{O}}}-1$ ). Because ILs can be regarded as incompressive fluids, the excessive accumulation of solutes leads to the extrusion of IL ions from the diffuse layer to the IL bulk. The decrease in the IL ions in the diffuse layer will suppress the refractive index enhancement and will consequently underestimate $\alpha_{\mathrm{R}}$. The quantitative assessment of the contribution of the extrusion would enable to more elaborately evaluate $\alpha_{\mathrm{R}}$ (and also $p$ ), although it needs the high-precision values of $\alpha_{\mathrm{C}}$ and $\alpha_{\mathrm{A}}$ in the IL itself.

\section{Conclusions}

In the present study, ESPR has been shown as a probe for the electrode reactions in ILs as exemplified using ferrocene derivatives as redox species. The relationship of the semi-integration/semi-differentiation has been confirmed for the ESPR response and the faradaic current. The inequality of the diffusion coefficients of the reduced and oxidized forms, a phenomenon peculiar to ILs, affects the magnitude of the ESPR response. Immediate applications of ESPR in ILs include batteries and electrodeposition using ILs, which involves more complicated electrode reactions than outer-sphere electron transfers investigated in the present study. Espe- 
cially, when the electrode reactions involve deposition on the electrode or etching of the electrode, not only the thickness change but also the surface roughness change would be able to be sensitively detected with ESPR, considering a fundamental study on the dependence of the SPR angle on the surface roughness. ${ }^{85,86}$ ESPR imaging for the electrode reaction in ILs will be another interesting application as has been proposed in electrolyte solutions. ${ }^{52}$

\section{Acknowledgements}

This work was partly supported by JSPS KAKENHI (Grant Numbers: JP26410149, JP26248004, and JP16H04216). 


\section{References}

(1) M. Armand, F. Endres, D. R. Macfarlane, H. Ohno, and B. Scrosati, Nat. Mater, 2009, 8, 621-629.

(2) D. R. MacFarlane, N. Tachikawa, M. Forsyth, J. M. Pringle, P. C. Howlett, G. D. Elliott, J. H. Davis, Jr., M. Watanabe, P. Simon, and C. A. Angell, Energy Environ. Sci., 2014, 7, 232-250.

(3) ed. F. Endres, A. P. Abbott, and D. R. MacFarlane, Electrodeposition from Ionic Liquids, Wiley-VCH, Weinheim, 2nd ed., 2017.

(4) H. Nakagawa, S. Izuchi, K. Kuwana, T. Nukuda, and Y. Aihara, J. Electrochem. Soc., 2003, 150, A695A700.

(5) S. Seki, Y. Kobayashi, H. Miyashiro, Y. Ohno, A. Usami, Y. Mita, N. Kihira, M. Watanabe, and N. Terada, J. Phys. Chem. B, 2006, 110, 10228-10230.

(6) S. Wilken, S. Xiong, J. Scheers, P. Jacobsson, and P. Johansson, J. Power Sources, 2015, 275, $935-942$.

(7) W. Kubo, T. Kitamura, K. Hanabusa, Y. Wada, and S. Yanagida, Chem. Commun., 2002 374-375.

(8) P. Wang, S. Zakeeruddin, I. Exnar, and M. Grätzel, Chem. Commun., 2002 2972-2973.

(9) S. Ito, S. M. Zakeeruddin, P. Comte, P. Liska, D. Kuang, and M. Grätzel, Nat. Photonics, 2008, 2, 693698.

(10) M. H. Chakrabarti, F. S. Mjalli, I. M. AlNashef, M. A. Hashim, M. A. Hussain, L. Bahadori, and C. T. J. Low, Renew. Sust. Energ. Rev., 2014, 30, 254-270.

(11) A. Ejigu, P. A. Greatorex-Davies, and D. A. Walsh, Electrochem. Commun., 2015, 54, 55-59.

(12) D. S. Silvester, Analyst, 2011, 136, 4871-4882.

(13) P. Hapiot and C. Lagrost, Chem. Rev., 2008, 108, 2238-2264.

(14) L. E. Barrosse-Antle, A. M. Bond, R. G. Compton, A. M. O’Mahony, E. I. Rogers, and D. S. Silvester, Chem.-Asian J., 2010, 5, 202-230.

(15) D. A. Walsh, K. R. J. Lovelock, and P. Licence, Chem. Soc. Rev., 2010, 39, 4185-4194.

(16) S. K. Sukardi, J. Zhang, I. Burgar, M. D. Horne, A. F. Hollenkamp, D. R. MacFarlane, and A. M. Bond, Electrochem. Commun., 2008, 10, 250-254.

(17) Y. Yamato, Y. Katayama, and T. Miura, J. Electrochem. Soc., 2013, 160, H309-H314.

(18) A. A. J. Torriero, Electrochim. Acta, 2014, 137, 235-244. 
(19) E. H. B. Anari, M. Romano, W. X. Teh, J. J. Black, E. Jiang, J. Chen, T. Q. To, J. Panchompoo, and L. Aldous, Chem. Commun., 2016, 52, 745-748.

(20) N. Frenzel, J. Hartley, and G. Frisch, Phys. Chem. Chem. Phys., 2017, 19, 28841-28852.

(21) C. Lagrost, D. Carrie, M. Vaultier, and P. Hapiot, J. Phys. Chem. A, 2003, 107, 745-752.

(22) N. Fietkau, A. Clegg, R. Evans, C. Villagran, C. Hardacre, and R. Compton, ChemPhysChem, 2006, 7, 1041-1045.

(23) N. Tachikawa, Y. Katayama, and T. Miura, Electrochem. Solid State Lett., 2009, 12, F39-F41.

(24) Y. Pan, W. E. Cleland, Jr., and C. L. Hussey, J. Electrochem. Soc., 2012, 159, F125-F133.

(25) C. L. Bentley, J. Li, A. M. Bond, and J. Zhang, J. Phys. Chem. C, 2016, 120, 16516-16525.

(26) C. Hussey, I. Sun, S. Strubinger, and P. Barnard, J. Electrochem. Soc., 1990, 137, 2515-2516.

(27) M. A. Vorotyntsev, V. A. Zinovyeva, D. V. Konev, M. Picquet, L. Gaillon, and C. Rizzi, J. Phys. Chem. B, 2009, 113, 1085-1099.

(28) H. Ueda, K. Nishiyama, and S. Yoshimoto, Phys. Chem. Chem. Phys., 2016, 18, 3558-3566.

(29) Z. Karpinski, C. Nanjundiah, and R. Osteryoung, Inorg. Chem., 1984, 23, 3358-3364.

(30) M. Lagunas, W. Pitner, J. van den Berg, and K. Seddon in Ionic Liquids as Green Solvents: Progress and Prospects, ed. Rodgers, RD and Seddon, KR, Vol. 856 of ACS Symposium Series; 2003 421-438.

(31) M. Matsumiya, M. Terazono, and K. Tokuraku, Electrochim. Acta, 2006, 51, 1178-1183.

(32) N. Tachikawa, Y. Katayama, and T. Miura, J. Electrochem. Soc., 2007, 154, F211-F216.

(33) E. I. Rogers, D. S. Silvester, D. L. Poole, L. Aldous, C. Hardacre, and R. G. Compton, J. Phys. Chem. C, 2008, 112, 2729-2735.

(34) M. J. A. Shiddiky, A. A. J. Torriero, J. M. Reyna-Gonzalez, and A. M. Bond, Anal. Chem., 2010, 82, 1680-1691.

(35) Y. Yang and L. Yu, Phys. Chem. Chem. Phys., 2013, 15, 2669-2683.

(36) T. Bernstein and F. Herbstein, Acta Crystallogr. B, 1968, B 24, 1640-1645.

(37) S. Scholz, M. Scheibitz, F. Schoedel, M. Bolte, M. Wagner, and H.-W. Lerner, Inorg. Chim. Acta, 2007, 360, 3323-3329.

(38) A. Kaintz, G. Baker, A. Benesi, and M. Maroncelli, J. Phys. Chem. B, 2013, 117, 11697-11708.

(39) A. Kaintz, G. Baker, A. Benesi, and M. Maroncelli, J. Phys. Chem. B, 2014, 118, 5615. 
(40) Y. Kimura, Y. Kida, Y. Matsushita, Y. Yasaka, M. Ueno, and K. Takahashi, J. Phys. Chem. B, 2015, 119, 8096-8103.

(41) J. C. Araque, S. K. Yadav, M. Shadeck, M. Maroncelli, and C. J. Margulis, J. Phys. Chem. B, 2015, 119, $7015-7029$.

(42) R. P. Daly, J. C. Araque, and C. J. Margulis, J. Chem. Phys., 2017, 147, 061102(1-5).

(43) J. Canongia Lopes and A. Padua, J. Phys. Chem. B, 2006, 110, 3330-3335.

(44) A. Triolo, O. Russina, H.-J. Bleif, and E. Di Cola, J. Phys. Chem. B, 2007, 111, 4641-4644.

(45) F. Chao, M. Costa, and A. Tadjeddine, J. Electroanal. Chem., 1992, 329, 313-327.

(46) W. Knoll, Annu. Rev. Phys. Chem., 1998, 49, 569-638.

(47) S. Wang, S. Boussaad, and N. J. Tao, in Biomolecular Films: Design, Function, and Applications, ed. J. F. Rusling, Marcell Dekker, New York, 2003 213-251.

(48) N. Zhang, R. Schweiss, Y. Zong, and W. Knoll, Electrochim. Acta, 2007, 52, 2869-2875.

(49) H. Raether, Surface Plasmons on Smooth and Rough Surfaces and on Gratings, Springer, Berlin, 1988.

(50) O. Andersson, C. Ulrich, F. Björefors, and B. Liedberg, Sens. Actuator B, 2008, 134, 545-550.

(51) R. A. A. Munoz, S. H. Toma, H. E. Toma, K. Araki, and L. Angnes, Electrochim. Acta, 2009, 54, 29712976.

(52) X. Shan, U. Patel, S. Wang, R. Iglesias, and N. Tao, Science, 2010, 327, 1363-1366.

(53) C. Hodneland and M. Mrksich, J. Am. Chem. Soc., 2000, 122, 4235-4236.

(54) X. Yao, J. Wang, F. Zhou, J. Wang, and N. Tao, J. Phys. Chem. B, 2004, 108, 7206-7212.

(55) A. K. Sheridan, P. Ngamukot, P. N. Bartlett, and J. S. Wilkinson, Sens. Actuator B-Chem., 2006, 117, $253-260$.

(56) L. L. Norman and A. Badia, Langmuir, 2007, 23, 10198-10208.

(57) S. Boussaad, J. Pean, and N. Tao, Anal. Chem., 2000, 72, 222-226.

(58) Y. Iwasaki, T. Horiuchi, and O. Niwa, Anal. Chem., 2001, 73, 1595-1598.

(59) S. Boussaad and N. Tao, J. Electroanal. Chem., 2003, 554, 233-239.

(60) R. Georgiadis, K. Peterlinz, J. Rahn, A. Peterson, and J. Grassi, Langmuir, 2000, 16, 6759-6762.

(61) X. Kang, Y. Jin, G. Cheng, and S. Dong, Langmuir, 2002, 18, 1713-1718. 
(62) A. Baba, J. Lubben, K. Tamada, and W. Knoll, Langmuir, 2003, 19, 9058-9064.

(63) F. Damos, R. Luz, and L. Kubota, Electrochim. Acta, 2006, 51, 1304-1312.

(64) N. Nishi, Y. Hirano, T. Motokawa, and T. Kakiuchi, Phys. Chem. Chem. Phys., 2013, 15, 11615-11619.

(65) M. Mezger, H. Schröder, H. Reichert, S. Schramm, J. S. Okasinski, S. Schöder, V. Honkimäki, M. Deutsch, B. M. Ocko, J. Ralston, M. Rohwerder, M. Stratmann, and H. Dosch, Science, 2008, 322, $424-428$.

(66) N. Nishi, Y. Yasui, T. Uruga, H. Tanida, T. Yamada, S. Nakayama, H. Matsuoka, and T. Kakiuchi, J. Chem. Phys., 2010, 132, 164705(1-6).

(67) N. Nishi, T. Uruga, and H. Tanida, J. Electroanal. Chem., 2015, 759, 129-136.

(68) N. Nishi, K. Minami, K. Motobayashi, M. Osawa, and T. Sakka, J. Phys. Chem. C, 2017, 121, 1658-1666.

(69) M. J. Earle, C. M. Gordon, N. V. Plechkova, K. R. Seddon, and T. Welton, Anal. Chem., 2007, 79, 758764.

(70) N. Nishi, J. Uchiyashiki, R. Oogami, and T. Sakka, Thin Solid Films, 2014, 571, 735-738.

(71) Kretschmann.E and H. Raether, Z. Naturforsch., 1968, A 23, 2135-2136.

(72) A. Rakić, A. Djurišić, J. Elazar, and M. Majewski, Appl. Optics, 1998, 37, 5271-5283.

(73) N. Nishi, K. Kasuya, and T. Kakiuchi, J. Phys. Chem. C, 2012, 116, 5097-5102.

(74) L. Lorenz, Ann. Physik, 1880, 247, 70-103.

(75) H. A. Lorentz, Ann. Physik, 1880, 245, 641-665.

(76) K. B. Oldham, J. C. Myland, and A. M. Bond, Electrochemical Science and Technology: Fundamentals and Applications, Wiley, Hoboken, 2012.

(77) Y. Yasui, Y. Kitazumi, R. Ishimatsu, N. Nishi, and T. Kakiuchi, J. Phys. Chem. B, 2009, 113, 3273-3276.

(78) S. Makino, Y. Kitazumi, N. Nishi, and T. Kakiuchi, Electrochem. Commun., 2011, 13, 1365-1368.

(79) I. Bou-Malham and L. Bureau, Soft Matter, 2010, 6, 4062-4065.

(80) M. Drüschler, N. Borisenko, J. Wallauer, C. Winter, B. Huber, F. Endres, and B. Roling, Phys. Chem. Chem. Phys., 2012, 14, 5090-5099.

(81) T. Jänsch, J. Wallauer, and B. Roling, J. Phys. Chem. C, 2015, 119, 4620-4626.

(82) E. I. Izgorodina, M. Forsyth, and D. R. MacFarlane, Phys. Chem. Chem. Phys., 2009, 11, 2452-2458. 
(83) C. L. Bentley, A. M. Bond, A. F. Hollenkamp, P. J. Mahon, and J. Zhang, Anal. Chem., 2013, 85, 22392245.

(84) U. Hohm, D. Goebel, and S. Grimme, Chem. Phys. Lett., 1997, 272, 328-334.

(85) D. Hornauer, H. Kapitza, and H. Raether, J. Phys. D-Appl. Phys., 1974, 7, L100-L102.

(86) A. Braundmeier, Jr. and E. Arakawa, J. Phys. Chem. Solids, 1974, 35, 517-520.

(87) P. Ugo, L. M. Moretto, M. De Leo, A. P. Doherty, C. Vallese, and S. Pentlavalli, Electrochim. Acta, 2010, $\mathbf{5 5}, 2865-2872$. 
Table 1: Volume of IL ions and redox species.

\begin{tabular}{ll}
\hline \multicolumn{1}{c}{ Ionic/redox species } & $\begin{array}{l}\text { Volume } \\
\left(\mathrm{cm}^{3} / \mathrm{mol}\right)\end{array}$ \\
\hline $\mathrm{TOMA}^{+}$ & 362 \\
$\mathrm{C}_{4} \mathrm{mim}^{+}$ & 116 \\
\hline $\mathrm{C}_{1} \mathrm{C}_{1} \mathrm{~N}^{-}$ & $123,{ }^{b} 128^{c}$ \\
\hline $\mathrm{Fc}^{2}$ & 113 \\
$\mathrm{FTA}^{+}$ & 196 \\
\hline
\end{tabular}

${ }^{a}$ Evaluated with B3LYP/6-311+G** level calculation. ${ }^{b} \mathrm{C} 1$ conformer. ${ }^{c} \mathrm{C} 2$ conformer. 
Table 2: Diffusion coefficients of the redox species at $25^{\circ} \mathrm{C}(298 \mathrm{~K})$ and the ESPR sensitivity $\left(\Delta \theta_{\text {lim }} / C_{\mathrm{R}, \text { bulk }}\right.$, $95 \%$ confidence interval).

\begin{tabular}{|c|c|c|c|c|c|}
\hline Ionic liquid & Redox species & $\begin{array}{l}D_{\mathrm{R}} \\
\left(10^{-12} \mathrm{~m}^{2} \mathrm{~s}^{-1}\right)\end{array}$ & $\begin{array}{l}D_{\mathrm{O}} \\
\left(10^{-12} \mathrm{~m}^{2} \mathrm{~s}^{-1}\right)\end{array}$ & $D_{\mathrm{R}} / D_{\mathrm{O}}$ & $\begin{array}{l}\Delta \theta_{\lim } / C_{\mathrm{R}, \mathrm{bulk}} \\
\left(\mathrm{mdeg} \mathrm{mM}^{-1}\right)\end{array}$ \\
\hline$\left[\mathrm{TOMA}^{+}\right]\left[\mathrm{C}_{1} \mathrm{C}_{1} \mathrm{~N}^{-}\right]$ & $\mathrm{Fc} / \mathrm{Fc}^{+}$ & 16 & 2.4 & 6.7 & $2.53 \pm 0.13$ \\
\hline$\left[\mathrm{TOMA}^{+}\right]\left[\mathrm{C}_{1} \mathrm{C}_{1} \mathrm{~N}^{-}\right]$ & $\mathrm{FTA}^{+} / \mathrm{FTA}^{2+}$ & 1.6 & 0.8 & 2.0 & $0.72 \pm 0.02$ \\
\hline$\left[\mathrm{C}_{4} \mathrm{mim}^{+}\right]\left[\mathrm{C}_{1} \mathrm{C}_{1} \mathrm{~N}^{-}\right]$ & $\mathrm{Fc} / \mathrm{Fc}^{+}$ & $32\left(17,{ }^{a} 27, b 29,{ }^{c} 30,{ }^{d} 37.7^{e}\right)$ & $24\left(26.5^{e}\right)$ & $1.3\left(1.43^{e}\right)$ & $0.8 \pm 0.3$ \\
\hline$\left[\mathrm{C}_{4} \mathrm{mim}^{+}\right]\left[\mathrm{C}_{1} \mathrm{C}_{1} \mathrm{~N}^{-}\right]$ & $\mathrm{FTA}^{+} / \mathrm{FTA}^{2+}$ & 22 & 17 & 1.3 & $0.72 \pm 0.07$ \\
\hline
\end{tabular}




\section{Figure captions}

Fig. 1 (a) $\mathrm{CVs}$ and (b) $\Delta \theta$ at the interface between gold and [TOMA $\left.{ }^{+}\right]\left[\mathrm{C}_{1} \mathrm{C}_{1} \mathrm{~N}^{-}\right]$with the presence (solid lines) and absence (dashed lines) of Fc at $25 \mathrm{mM}$. (c) Baseline-subtracted $\Delta \theta$. Scan rate: 10 (red), 30 (blue), and 50 (black) $\mathrm{mV} \mathrm{s}^{-1}$. The open circles in (a) and (c) are semi-differentiated $\Delta \theta$ and semi-integrated $I$, respectively.

Fig. $2 \Delta \theta / C_{R \text {,bulk }}$ response during $\mathrm{CV}(\mathrm{a}, \mathrm{b})$ at the $\left[\mathrm{TOMA}^{+}\right]\left[\mathrm{C}_{1} \mathrm{C}_{1} \mathrm{~N}^{-}\right] \mid$gold interface and $(\mathrm{c}, \mathrm{d})$ at the $\left[\mathrm{C}_{4} \mathrm{mim}^{+}\right]\left[\mathrm{C}_{1} \mathrm{C}_{1} \mathrm{~N}^{-}\right] \mid \mathrm{gold}$ interface with the presence of (a,c) Fc and (b,d) $\mathrm{FTA}^{+}$in the ILs. Scan rate: 10 (red), 30 (blue), and 50 (black) $\mathrm{mV} \mathrm{s}^{-1}$.

Fig. 3 ESPR sensitivity, $\Delta \theta_{\text {lim }} / C_{\mathrm{R} \text {,bulk }}$, for the combination of $\left[\mathrm{TOMA}^{+}\right]\left[\mathrm{C}_{1} \mathrm{C}_{1} \mathrm{~N}^{-}\right]-\mathrm{Fc} / \mathrm{Fc}^{+}\left(\operatorname{solid}\right.$ circle), $\left[\mathrm{TOMA}^{+}\right]\left[\mathrm{C}_{1} \mathrm{C}_{1} \mathrm{~N}^{-}\right]-$ $\mathrm{FTA}^{+} / \mathrm{FTA}^{2+}$ (solid square), $\left[\mathrm{C}_{4} \mathrm{mim}^{+}\right]\left[\mathrm{C}_{1} \mathrm{C}_{1} \mathrm{~N}^{-}\right]-\mathrm{Fc} / \mathrm{Fc}^{+}$(open circle), and $\left[\mathrm{C}_{4} \mathrm{mim}^{+}\right]\left[\mathrm{C}_{1} \mathrm{C}_{1} \mathrm{~N}^{-}\right]-\mathrm{FTA}^{+} / \mathrm{FTA}^{2+}$ (open square). The solid line is the fitted curve from Eq.(6). 


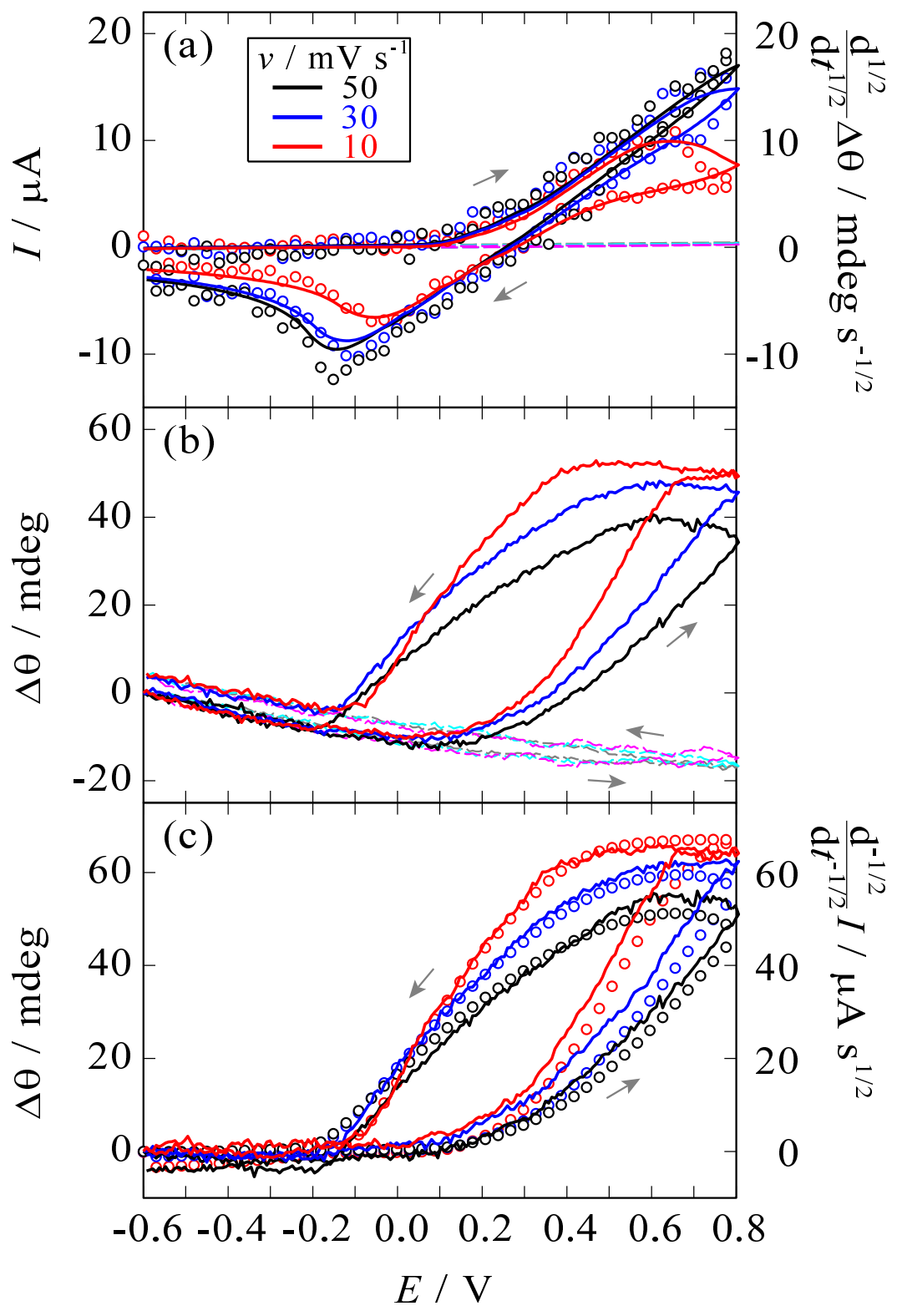

Fig.1 (Nishi et al.) 


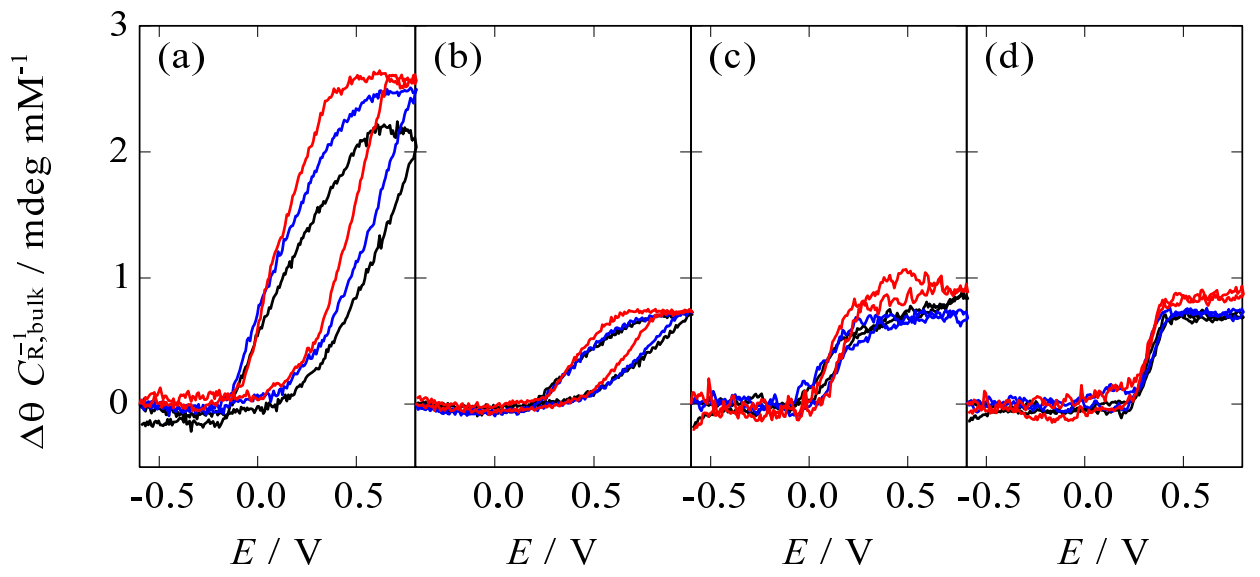

Fig.2 (Nishi et al.) 


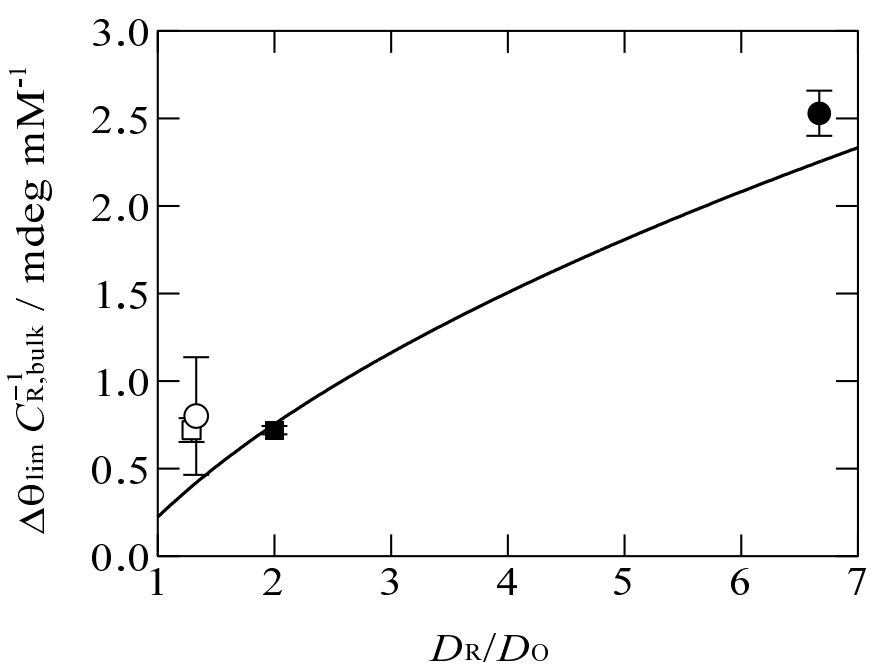

Fig.3 (Nishi et al.) 